Egyptian Journal of Aquatic Biology \& Fisheries

Zoology Department, Faculty of Science,

Ain Shams University, Cairo, Egypt.

ISSN $1110-6131$

Vol. 24(1): 349 - 370 (2020)

www.ejabf.journals.ekb.eg

\title{
Grain size distribution and environmental implications of Rosetta beach, Mediterranean Sea coast, Egypt
}

\author{
Eman A. Elsherif ${ }^{1, *}$, Amani Badawi ${ }^{1}$, Tarek Abdelkader ${ }^{2}$ \\ ${ }^{1}$ Marine Geology lab, Marine Environmental Division, National Institute of Oceanography and \\ Fisheries (NIOF), Alexandria 21556, Egypt. \\ ${ }^{2}$ Geology Department, Faculty of Science, Tanta University, Tanta 31527, Egypt. \\ *Corresponding Author: emanadelelsherif@yahoo.com
}

\section{ARTICLE INFO} Article History:

Received: Sep, 16, 2019

Accepted: Dec. 27, 2019

Online: Jan. 2020

Keywords:

Mediterranean Sea

Rosetta beach

Grain-size analysis

Depositiona

Environment

Hydrodynamic condition

Mode of transportation
ABSTRACT

Grain-size analysis of beach sediments along Rosetta beach of the Nile delta coast has been carried out to reveal the depositional environment condition, energy and hydrodynamic conditions, as well as the mode of transportation along the study area. In total 56 beach samples were collected, distributed along 3 profiles parallel to the shoreline and covering the shoreline, semi-wet area, and the dry backshore area. The study showed the great sensitivity of the interrelationships of various grain size statistical parameters (mean size, sorting, skewness, and kurtosis) to the slight variations in the compositional formula of the sediment mixture. Distribution of the textural parameters revealed the dominance of unimodal pure sand sediments, mainly Nile sand sources. The fluctuation between moderately well-sorted to well-sorted sediments and from coarse skewed to fine skewed under leptokurtic to platykurtic nature was distinguished at different localities and relevant environmental implications. Different discrimination tools as bivariate cross plot of grain size parameters, Linear Discrimination Functions (LDF), skewness and kurtosis relationship as a non-dimensional expression of sediment/energy simulation, Energy Process diagram, and mode of transportation (C-M diagram), indicates the marine signature followed the riverine input as a function of the sediments locality. Depositional processes were mainly hydraulically controlled through active energy processes of the marine environment. The fluvial nature of sediment demonstrated the graded suspension and saltation modes as the prime factors for transportation, influenced by marine and turbidity environment actions, within a shallow agitated marine environment.

\section{INTRODUCTION}

The Nile Delta coast of the Mediterranean Sea extends from Alexandria to Port Said, (250 km long), consists of deltaic sandy beaches of medium to very fine sands. It hosts the majority of the country's population and industrial activities. The heavily discharge of the Nile River fluvial deposition to the Mediterranean Sea through its main branches, gradually developed the delta (Late Pliocene), since 6000-8000 years B.P. (Stanley, 1990; Said, 1993; Stanley and Warne, 1993). However, marine and other environmental processes transported some of the discharged sediments in cross-shore and 
alongshore directions on the continental shelf (Stanley, 1990). Generally, strong coastal current processes, controlled by wind-and wave-driven currents, associated with the eastern Mediterranean gyre (Goldsmith and Golik, 1980; Inman and Jenkins, 1984; Said, 1993) is the main controller of the Egyptian Mediterranean Sea coast.

Recently, the Nile Delta coastal zone of Egypt is subject to severe threats, in particular Rosetta promontory area, due to natural and anthropogenic factors, such as shoreline erosion, deterioration of coastal lagoons, sea level rise, delta subsidence, excessive land use, and pollution from oil industry and transport; these activities have significant impact on sustainable development and environmental protection. Rosetta area hosts different land uses represented by new Rosetta City, Ghalyoun ponds, industrial areas, and mining activities. Both the eastern and western shores of Rosetta promontory are considered as relatively stable protected shores and classified as moderate vulnerability coastlines (Frihy, 2017).

Coastal erosion is considered as the major threatens along the Rosetta area. Dramatic changes of the hydrologic regime in the Nile Delta, after the construction of the Aswan High Dam in 1964, have resulted in the stoppage of sediments and flood water from reaching the Mediterranean Sea (Stanley and Warne, 1993; Fanos et al., 1995; Frihy and Dewidar, 2003; Stanley et al., 2004; Torab and Azab, 2007; Hamouda et al., 2014; Ghoneim et al., 2015). Massive coastal structures have been built to protect the coastal Rosetta area where the seawall succeeded in that, the groins construction in the contrary caused a local erosion of about $25 \mathrm{~m}$ year-1 along the down coast, which locates eastward to the massive coastal structures built eastward to the Rosetta promontory (Ghoneim et al., 2015; Frihy, 2017).

Additionally, significant threatens affect the Nile Delta coast such as the sea level rise and delta subsidence, where about $31 \%$ of the Nile Delta will be inundated if the sea level rises by $100 \mathrm{~cm}$ above its current level (Hereher, 2010). The most pessimistic scenario is coupling of sea level rise with the delta subsidence, where the subsidence rates range from 0.03 to $4.5 \mathrm{~mm} / \mathrm{yr}$ along the northern part of the Nile Delta (Marriner $\boldsymbol{e t}$ al., 2012). This will be accompanied by relocation of millions of people southward to the present shoreline, contamination of water resources, and loss of fertile agricultural land.

Grain-size characteristics of sediments are widely used by geologists to reveal transportation processes, hydrodynamic conditions and depositional environments. Each sedimentary environment supposedly exhibits distinctively different grain-size characteristics, 'fingerprint' that distinguish them from sediments deposited in different environments (Blott and Pye, 2001; Boggs, 2009). Grain-size analysis is generally used to define and reconstruct the depositional environments of clastic sediments (Passega, 1957, 1964; Passega and Byramjee, 1969). Longshore and cross-shore grain-size distribution reflect the operated waves and currents that result in sorting process of beach sand ( Frihy and Komar, 1993; Frihy et al., 1995). Grain sorting analyses assist in planning and designing engineering structures, undertaking beach nourishment projects, and in the exploration, discovery, and evaluation of placer deposits (Frihy, 2007).

The objective of this study is to manifest the distribution of grain size parameters, apply their relevant environmental implication to reveal depositional environment and assist the efficiency of using the discriminating environmental boundaries, as well as interpret the energy and hydrodynamic conditions within the depositional environment, in addition, to delineate the mode of transportation of the study area sediments. 


\section{MATERIALS AND METHODS}

The study area is located along the north-west region of the Nile delta on the coast of the Mediterranean Sea. It covers onshore area (beach) adjacent to the western and eastern parts of Rosetta Promontory extending from the shoreline to bachshore, along three profiles (Fig. 1). The western side covers Altabiya-Rosetta area, extends $7 \mathrm{~km}$ parallel and $40 \mathrm{~m}$ perpendicular to the shoreline west of Rosetta distributary mouth. The eastern side covers Ghalyoun ponds, Abu-Khashabah area, to Kom-Mashaal area extends $20 \mathrm{~km}$ parallel and $40 \mathrm{~m}$ perpendicular to the shore line, and considered as a western sector of the sand bar separating the Burullus Lake from the Mediterranean Sea. It is bounded by the international highway to the south and Elsahel coastal drain to the north.

Fifty-six beach sediment samples were collected from the eastern and western areas of the Rosetta promontory of the Nile Delta coast. The collected samples are distributed along 19 points, spaced by 1 to $3 \mathrm{~km}$, perpendicular to the shoreline and extend into the land from the beach line to 40-50 m south of the shoreline, including one sample from the river bed. The samples are distributed along 3 main profiles parallel to the shoreline; the first profile A starts at the shoreline; the second B is taken from the semi -wet area at less than $20 \mathrm{~m}$ from the shoreline, and the third profile $\mathrm{C}$ is collected from the dry area at 40$50 \mathrm{~m}$ or less. Each representative beach sample $(1-2 \mathrm{~kg})$ was collected from the upper 15 $\mathrm{cm}$ of the sand beach face using a plastic scoop and kept in plastic bags. The position of each station along the study area was determined using a GPS and illustrated in Fig. 1.

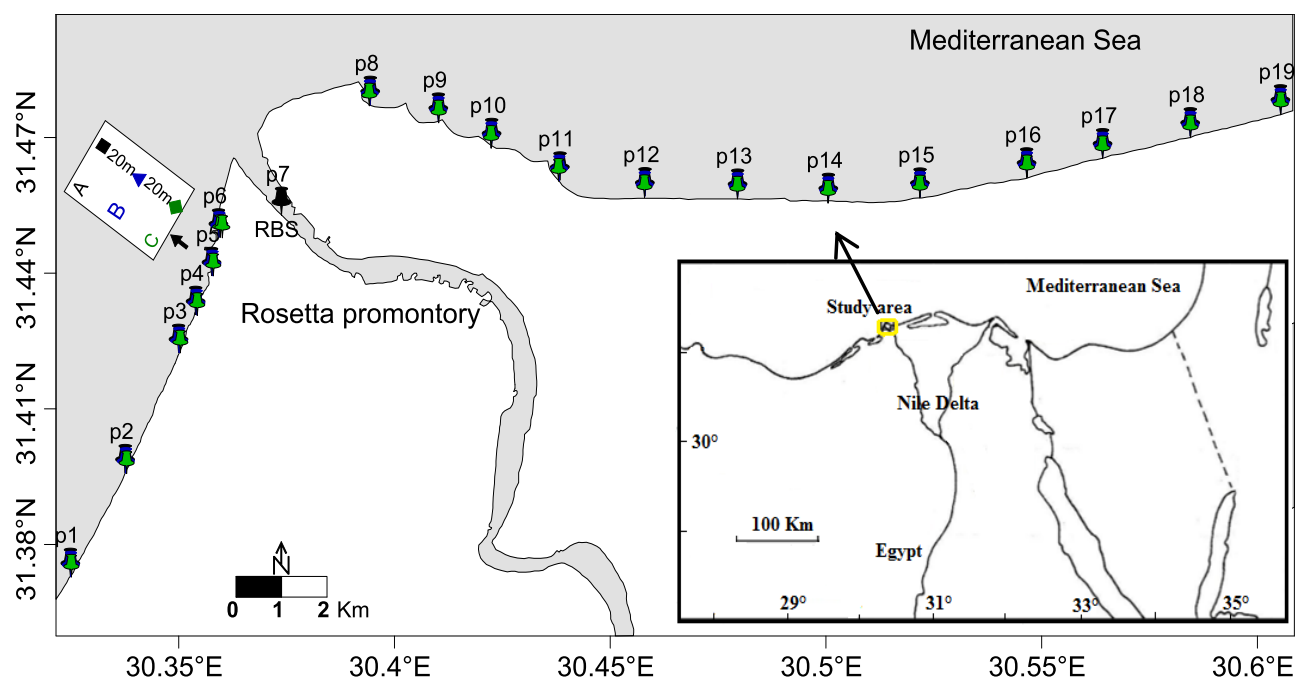

Fig. 1. The study area and the locations of the sediment samples profiles along Rosetta beach area.

A representative sample weighing about $50 \mathrm{gm}$ of the dried samples was subjected to grain-size analysis. Mechanical sieving technique was applied to all samples using a standard set of sieves, mounted on an electric shaker. Analytical results were used to draw the frequency curves. Four statistical parameters; graphic mean size $\left(\mathrm{M}_{\mathrm{z}}\right)$, inclusive graphic standard deviation (sorting) $\left(\sigma_{\mathrm{I}}\right)$, skewness $\left(\mathrm{Sk}_{\mathrm{I}}\right)$ and kurtosis $\left(\mathrm{K}_{\mathrm{G}}\right)$ for each sample were calculated according to (Folk and Ward, 1957) using GRADISTAT program software (Blott and Pye, 2001). The graphic mean size $\left(\mathrm{M}_{\mathrm{z}}\right)$ represent the average size of the sediment distribution by phi mean size, and considered as an index of energy conditions that governed by the average intensity of the transporting medium (Passega, 1964). The inclusive standard deviation $\left(\sigma_{I}\right)$ measures the sorting or uniformity 
of the grain size distribution and indicates the fluctuations in the hydrodynamic energy conditions of depositional environment (Sahu, 1964). The inclusive graphic skewness $\left(\mathrm{Sk}_{\mathrm{I}}\right)$ is a function of symmetry of grain size distribution that reflects the spread of the grains in the tail distribution. The graphic kurtosis $\left(\mathrm{K}_{\mathrm{G}}\right)$ reflects the peakedness or the sharpness of the grain size distribution (Folk, 1966) and is a significant parameter in delineating the environmental energy (Duane, 1964) due to its sensitivity to subpopulation mixing. Bivariate plots of the four statistical grain size parameters as interrelationships scatter graph were carried out to identify depositional settings. The scatter diagram plots of the grain size statistical parameters with discriminating environmental boundaries after (Friedman, 1967; Moiola and Weiser, 1968) are applied in the present study; these diagrams are very useful to bring out the mode and environment of deposition. The linear discriminant functions (LDF) were calculated as suggested by (Sahu, 1964) to discriminate the depositional conditions of the sediments. Skewness and kurtosis relationship was interpreted as an expression of sediment/energy simulation (Sly, 1978). The Energy process diagram for the study sediment samples was plotted after (Stewart, 1958). The CM plot was applied according to (Passega, 1957, 1964; Passega and Byramjee, 1969) to reveal transportation mechanism.

\section{RESULTS}

\section{Statistical parameters}

Sand represents the majority (about 99.8\%) of the sediment content, where the fine sand fraction averages about $79.1 \%$ of the sand content. The sediment distribution mode of the three profiles is 2.5 $\Phi$ which is the pure sand mode (Folk and Ward, 1957). The values of the four statistical parameters are represented in Table 1 where the summary of each parameter sector frequency is given in Table 2.

Table 1. Statistical parameters of the grain size distribution along the profile samples.

\begin{tabular}{|c|c|c|c|c|c|c|c|c|c|c|}
\hline \multirow{2}{*}{$\begin{array}{c}\text { Sample } \\
\text { number } \\
\text { (S.No.) }\end{array}$} & \multicolumn{2}{|c|}{$\mathbf{M}_{z},($ mean size $)$} & \multicolumn{2}{|c|}{$\sigma_{\mathrm{I}},($ sorting $)$} & \multicolumn{2}{|c|}{$\mathbf{S k}_{\mathbf{I}}$, (skewness) } & \multicolumn{2}{|c|}{$\mathbf{K}_{\mathrm{G}}$, (kurtosis) } & \multirow{2}{*}{$\begin{array}{c}\mathrm{M}= \\
\text { median } \\
(\mu \mathrm{m})\end{array}$} & \multirow{2}{*}{$\begin{array}{c}\mathrm{C}=\text { one } \\
\text { percentile } \\
(\mu \mathrm{m})\end{array}$} \\
\hline & value & Descr. & value & Descr. & value & Descr. & Value & Descr. & & \\
\hline A1 & 1.79 & M.S. & 0.59 & M.W.So. & 0.26 & F.Sk. & 0.93 & M.Ku. & 307 & 482 \\
\hline A2 & 2.38 & F.S. & 0.48 & W.So. & -0.21 & C.Sk. & 1.11 & L.Ku. & 188 & 384 \\
\hline A3 & 2.56 & F.S. & 0.44 & W.So. & 0.17 & F.Sk. & 1.10 & M.Ku. & 169 & 287 \\
\hline A4 & 2.47 & F.S. & 0.51 & M.W.So. & -0.04 & N.Sym. & 1.28 & L.Ku. & 180 & 353 \\
\hline A5 & 2.46 & F.S. & 0.44 & W.So. & -0.16 & C.Sk. & 1.08 & M.Ku. & 181 & 392 \\
\hline A6 & 2.47 & F.S. & 0.42 & W.So. & -0.14 & C.Sk. & 1.04 & M.Ku. & 180 & 366 \\
\hline A7(RBS) & 2.49 & F.S. & 0.47 & W.So. & -0.03 & N.Sym. & 1.21 & L.Ku. & 177 & 358 \\
\hline A8 & 2.51 & F.S. & 0.51 & M.W.So. & 0.02 & N.Sym. & 1.29 & L.Ku. & 175 & 329 \\
\hline A9 & 2.01 & F.S. & 0.63 & M.W.So. & 0.00 & N.Sym. & 0.74 & P.Ku. & 248 & 473 \\
\hline A10 & 2.52 & F.S. & 0.52 & M.W.So. & 0.03 & N.Sym. & 1.30 & L.Ku. & 174 & 318 \\
\hline A11 & 2.44 & F.S. & 0.47 & W.So. & -0.14 & C.SK. & 1.14 & L.Ku. & 183 & 420 \\
\hline A12 & 2.30 & F.S. & 0.54 & M.W.So. & -0.25 & C.Sk. & 1.08 & M.Ku. & 193 & 392 \\
\hline A13 & 2.49 & F.S. & 0.46 & W.So. & -0.03 & N.Sym. & 1.19 & L.Ku. & 177 & 406 \\
\hline A14 & 2.50 & F.S. & 0.39 & W.So. & 0.04 & N.Sym. & 0.94 & M.Ku. & 176 & 307 \\
\hline A15 & 2.47 & F.S. & 0.46 & W.So. & -0.09 & N.Sym. & 1.15 & L.Ku. & 179 & 325 \\
\hline A16 & 2.46 & F.S. & 0.47 & W.So. & -0.11 & C.Sk. & 1.16 & L.Ku. & 182 & 348 \\
\hline A17 & 2.52 & F.S. & 0.44 & W.So. & 0.10 & F.Sk. & 1.11 & M.Ku. & 173 & 500 \\
\hline A18 & 2.51 & F.S. & 0.55 & M.W.So. & 0.01 & N.Sym. & 1.35 & L.Ku. & 175 & 329 \\
\hline
\end{tabular}




\begin{tabular}{|c|c|c|c|c|c|c|c|c|c|c|}
\hline A19 & 2.56 & F.S. & 0.51 & M.W.So. & 0.08 & N.Sym. & 1.23 & L.Ku. & 169 & 329 \\
\hline B1 & 2.49 & F.S. & 0.36 & W.So. & -0.05 & N.Sym. & 0.82 & P.Ku. & 178 & 353 \\
\hline B2 & 2.38 & F.S. & 0.48 & W.So. & -0.21 & C.Sk. & 1.11 & L.Ku. & 187 & 378 \\
\hline B3 & 2.55 & F.S. & 0.43 & W.So. & 0.16 & F.Sk. & 1.08 & M.Ku. & 170 & 287 \\
\hline B4 & 2.59 & F.S. & 0.52 & M.W.So. & 0.14 & F.Sk. & 1.18 & L.Ku. & 168 & 329 \\
\hline B5 & 2.83 & F.S. & 0.62 & M.W.So. & 0.18 & F.Sk. & 0.80 & P.Ku. & 148 & 329 \\
\hline B6 & 2.27 & F.S. & 0.57 & M.W.So. & -0.24 & C.Sk. & 1.03 & M.Ku. & 196 & 378 \\
\hline B8 & 2.56 & F.S. & 0.45 & W.So. & 0.16 & F.Sk. & 1.09 & M.Ku. & 169 & 297 \\
\hline B9 & 2.48 & F.S. & 0.39 & W.So. & -0.11 & C.Sk. & 0.95 & M.Ku. & 179 & 353 \\
\hline B10 & 2.50 & F.S. & 0.50 & M.W.So. & 0.01 & N.Sym. & 1.29 & L.Ku. & 176 & 334 \\
\hline B11 & 2.55 & F.S. & 0.43 & W.So. & 0.16 & F.Sk. & 1.09 & M.Ku. & 170 & 307 \\
\hline B12 & 2.54 & F.S. & 0.44 & W.So. & 0.15 & F.Sk. & 1.07 & M.Ku. & 172 & 307 \\
\hline B13 & 2.56 & F.S. & 0.44 & W.So. & 0.16 & F.Sk. & 1.10 & M.Ku. & 169 & 297 \\
\hline B14 & 2.56 & F.S. & 0.42 & W.So. & 0.16 & F.Sk. & 1.08 & M.Ku. & 169 & 253 \\
\hline B15 & 2.51 & F.S. & 0.37 & W.So. & 0.08 & N.Sym. & 0.87 & P.Ku. & 175 & 307 \\
\hline B16 & 2.45 & F.S. & 0.44 & W.So. & -0.16 & C.Sk. & 1.08 & M.Ku. & 182 & 329 \\
\hline B17 & 2.56 & F.S. & 0.45 & W.So. & 0.16 & F.Sk. & 1.10 & M.Ku. & 169 & 435 \\
\hline B18 & 2.55 & F.S. & 0.43 & W.So. & 0.16 & F.Sk. & 1.08 & M.Ku. & 171 & 406 \\
\hline B19 & 2.58 & F.S. & 0.44 & W.So. & 0.17 & F.Sk. & 1.11 & L.Ku. & 167 & 250 \\
\hline $\mathrm{C} 1$ & 2.51 & F.S. & 0.37 & W.So. & 0.08 & N.Sym. & 0.88 & P.Ku. & 175 & 329 \\
\hline $\mathrm{C} 2$ & 2.40 & F.S. & 0.47 & W.So. & -0.18 & C.Sk. & 1.11 & L.Ku. & 190 & 435 \\
\hline $\mathrm{C} 3$ & 2.69 & F.S. & 0.54 & M.W.So. & 0.25 & F.Sk. & 1.09 & M.Ku. & 162 & 318 \\
\hline $\mathrm{C} 4$ & 2.59 & F.S. & 0.48 & W.So. & 0.18 & F.Sk. & 1.10 & M.Ku. & 167 & 307 \\
\hline C5 & 2.61 & F.S. & 0.54 & M.W.So. & 0.14 & F.Sk. & 1.19 & L.Ku. & 167 & 353 \\
\hline C6 & 2.48 & F.S. & 0.60 & M.W.So. & -0.01 & N.Sym. & 1.34 & L.Ku. & 179 & 392 \\
\hline C6 & 2.60 & F.S. & 0.67 & M.W.So. & 0.06 & N.Sym. & 1.30 & L.Ku. & 171 & 406 \\
\hline $\mathrm{C} 8$ & 2.26 & F.S. & 0.66 & M.W.So. & -0.12 & C.Sk. & 1.08 & M.Ku. & 196 & 435 \\
\hline C9 & 2.45 & F.S. & 0.55 & M.W.So. & -0.05 & N.Sym. & 1.31 & L.Ku. & 183 & 435 \\
\hline C10 & 2.63 & F.S. & 0.50 & W.So. & 0.22 & F.Sk. & 1.11 & M.Ku. & 164 & 287 \\
\hline $\mathrm{C} 11$ & 2.42 & F.S. & 0.63 & M.W.So. & -0.07 & N.Sym. & 1.36 & L.Ku. & 182 & 615 \\
\hline $\mathrm{C} 12$ & 2.71 & F.S. & 0.55 & M.W.So. & 0.25 & F.Sk. & 1.06 & M.Ku. & 160 & 378 \\
\hline C13 & 2.68 & F.S. & 0.52 & M.W.So. & 0.24 & F.Sk. & 1.09 & M.Ku. & 162 & 287 \\
\hline C14 & 2.52 & F.S. & 0.41 & W.So. & 0.12 & F.Sk. & 1.01 & M.Ku. & 174 & 366 \\
\hline $\mathrm{C} 15$ & 2.49 & F.S. & 0.40 & W.So. & -0.06 & N.Sym. & 0.97 & M.Ku. & 177 & 341 \\
\hline C16 & 2.57 & F.S. & 0.44 & W.So. & 0.17 & F.Sk. & 1.11 & L.Ku. & 168 & 258 \\
\hline $\mathrm{C} 17$ & 2.53 & F.S. & 0.40 & W.So. & 0.13 & F.Sk. & 1.00 & M.Ku. & 173 & 329 \\
\hline C18 & 2.75 & F.S. & 0.58 & M.W.So. & 0.26 & F.Sk. & 1.02 & M.Ku. & 157 & 307 \\
\hline C19 & 2.58 & F.S. & 0.45 & W.So. & 0.17 & F.Sk. & 1.11 & L.Ku. & 167 & 287 \\
\hline avg. & 2.50 & F.S. & 0.49 & W.So. & 0.04 & F.Sk. & 1.10 & M.Ku. & 179 & 357 \\
\hline
\end{tabular}

Note: M.S. (Medium sand), F.S. (Fine sand), M.W. (Moderately well sorted), W.So. (Well sorted), F.Sk. (Fine skewed), N.Sym. (Near symmetrical), C.Sk. (Coarse skewed), L.Ku. (Leptokurtic), M.Ku. (Mesokurtic), P.Ku. (Platykurtic).

Profile A mean size values $\left(\mathrm{M}_{\mathrm{z}}\right)$ ranges from $1.79 \Phi$ (medium sand) to $2.56 \Phi$ (fine sand) with average of $2.42 \Phi$ (fine sand) including the river bed sample (RBS) $2.49 \Phi$ (fine sand). The coarsest value of mean size is recorded at sample site A1, west of Rosetta mouth, with value of $1.79 \Phi$ (medium sand). Most of profile A's samples tend to be clustered left to the value of $2.50 \Phi(63.2 \%)$. The calculated mean values of profile B range from $2.27 \Phi$ to $2.83 \Phi$ (fine sand) with average of $2.53 \Phi$ (fine sand). The samples of 
profile $\mathrm{B}$ tend to be clustered right to the value of $2.5 \Phi(72.2 \%)$. The calculated mean values of profile $\mathrm{C}$ range from $2.26 \Phi$ to $2.75 \Phi$ (fine sand) with average of $2.55 \Phi$ (fine sand). The samples of profile $\mathrm{C}$ tend to be clustered right to the value of $2.50 \Phi(68.4 \%)$.

Table 2. Summary of grain size parameters (frequency of each sector).

\begin{tabular}{|c|c|c|c|}
\hline \multicolumn{4}{|c|}{ Summary of grain size parameters } \\
\hline & Profile A & Profile B & Profile $\mathrm{C}$ \\
\hline \multicolumn{4}{|c|}{ Mean size $\left(M_{z}\right)$} \\
\hline M.S. & 5.3 & 0.0 & 0.0 \\
\hline F.S. & 94.7 & 100.0 & 100.0 \\
\hline \multicolumn{4}{|c|}{ Sorting $\left(\sigma_{I}\right)$} \\
\hline W.So. & 57.9 & 77.8 & 47.4 \\
\hline M.W.So. & 42.1 & 22.2 & 52.6 \\
\hline \multicolumn{4}{|c|}{ Skewness $\left(\mathbf{S k}_{\mathbf{I}}\right)$} \\
\hline C.Sk. & 31.6 & 22.2 & 10.5 \\
\hline N.Sym. & 52.6 & 16.7 & 31.6 \\
\hline F.Sk. & 15.8 & 61.1 & 57.9 \\
\hline \multicolumn{4}{|c|}{$\operatorname{Kurtosis}\left(\mathbf{K}_{\mathbf{G}}\right)$} \\
\hline P.Ku. & 5.3 & 16.7 & 5.3 \\
\hline M.Ku. & 36.8 & 61.1 & 52.6 \\
\hline L.Ku. & 57.9 & 22.2 & 42.1 \\
\hline
\end{tabular}

The sorting $\left(\sigma_{\mathrm{I}}\right)$ values depict that profile A, is characterized by moderately wellsorted to well-sorted character, where the values range from 0.51-0.63 $\Phi$ (moderately well-sorted; $42.1 \%$ ) to $0.39-0.48 \Phi$ (well-sorted; $57.9 \%$ ), with average of $0.49 \Phi$ (wellsorted). The value of sorting in the river bed sample is $0.47 \Phi$. Profile B shows a better sorting than profile $\mathrm{A}$ and $\mathrm{C}$ where only four samples values are moderately well-sorted ranging from $0.50-0.62 \Phi(22.2 \%)$ whereas the remaining samples are well-sorted ranging

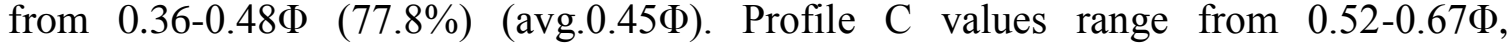
(moderately well-sorted; 52.6\%) and 0.37-0.50Ф, (well-sorted; 47.4\%) (avg. 0.51Ф).

The skewness $\left(\mathrm{SK}_{\mathrm{I}}\right)$ values reveal that profile $\mathrm{A}$ is dominated by near symmetrical nature $(-0.09: 0.08)$ and represented by $52.6 \%$ followed by coarse skewed $(-0.25:-0.11)$ represented by $31.6 \%$ to fine skewed $(0.10: 0.26)$ represented by $15.8 \%$ with average of 0.03 . The river bed sample has a negative value of -0.03 . Most of profile B samples exhibit fine skewed character $(0.14: 0.18)(61.1 \%)$, which is represented by a tail of excess fine particles, followed by coarse skewed character(-0.24:-0.11) (22.2\%) then near symmetrical nature(-0.05:0.08) (16.7\%). Fine skewed nature $(0.12: 0.26)(57.9 \%)$ prevails in profile $\mathrm{C}$ followed by near symmetrical nature $(-0.07: 0.08)(31.6 \%)$ then coarse skewed character (-0.18:-0.12) (10.5\%). Profile A samples are mostly negatively skewed nature $(52.6 \%)$ while profile $\mathrm{B}$ and profile $\mathrm{C}$ are characterized by positively skewed nature $(72.2 \%$, and $68.4 \%)$ respectively.

Kurtosis $\left(\mathrm{K}_{\mathrm{G}}\right)$ values for profile A ranged from 1.11-1.35 (57.9\%) leptokurtic followed by $0.93-1.11(36.8 \%)$ mesokurtic with one sample showed platykurtic nature (0.74) (5.3\%). The river bed sample value is 1.21; leptokurtic. Most samples of profile B exhibit mesokurtic nature ranging from $0.95-1.10(61.1 \%)$ followed by leptokurtic nature 1.11-1.29 (22.2\%) then platykurtic nature 0.80-0.87 (16.7\%). Samples of profile C values show mesokurtic ranges from 0.97-1.11 (52.6\%) followed by leptokurtic ranges1.11-1.36 $(42.1 \%)$ then one sample shows platykurtic nature $0.88(5.3 \%)$. 


\section{Linear discriminate function (LDF)}

The Linear discriminate function (LDF) is a statistical analysis of the sediments used to interpret the energy and fluidity factor variations and correlate the different processes of the depositional environment (Sahu, 1964). Sahu (1964) stated four equations for four discriminant functions (Y1, Y2, Y3, and Y4) to distinguish between the sedimentary environments. The discriminant functions have been calculated where $\mathrm{M}_{\mathrm{z}}, \sigma_{\mathrm{I}}^{2}, \mathrm{Sk}_{\mathrm{I}}, \mathrm{K}_{\mathrm{G}}$ is the mean size, variance (standard deviation) ${ }^{\wedge}$, skewness, kurtosis respectively in accordance to these equations:

Y1 $($ aeolian: beach $)=-3.5688 \mathrm{M}_{\mathrm{z}}+3.7016 \sigma_{\mathrm{I}}^{2}-2.0766 \mathrm{Sk}_{\mathrm{I}}+3.1135 \mathrm{~K}_{\mathrm{G}}$.

If Y1 is <-2.7411, the environment is beach and if Y1 is >-2.7411, the environment is aeolian.

$\mathrm{Y} 2$ (beach: shallow agitated $)=15.6534 \mathrm{M}_{\mathrm{z}}+65.7091 \sigma_{\mathrm{I}}^{2}+18.1071 \mathrm{Sk}_{\mathrm{I}}+18.5043 \mathrm{~K}_{\mathrm{G}}$.

If $\mathrm{Y} 2$ is $<63.3650$, the environment is shallow agitated marine and if $\mathrm{Y} 2$ is $>63.3650$ indicates beach deposition.

$\mathrm{Y} 3($ shallow marine: fluvial $)=0.2852 \mathrm{M}_{\mathrm{Z}}-8.7604 \sigma_{\mathrm{I}}^{2}-4.8932 \mathrm{Sk}_{\mathrm{I}}+0.0482 \mathrm{~K}_{\mathrm{G}}$.

If $\mathrm{Y} 3$ is <-7.4190, the environment is shallow agitated marine and if $\mathrm{Y} 3$ is $>-7.4190$ indicates fluvial (deltaic deposition).

Y4 (fluvial: turbidity) $=0.7215 \mathrm{M}_{\mathrm{z}}-0.4030 \sigma_{\mathrm{I}}^{2}+6.7322 \mathrm{Sk}_{\mathrm{I}}+5.2927 \mathrm{~K}_{\mathrm{G}}$.

If $\mathrm{Y} 4$ is $<9.8433$, the fluvial deposition domains and if $\mathrm{Y} 4$ is $>9.8433$ indicates turbidity current deposition.

Calculating the linear discriminate functions (Y1, Y2, Y3, and Y4) (Table 3), the values ranged from -6.57 to $-2.78,61.53$ to $95.15,-3.71$ to -0.02 , and 5.21 to 9.24 respectively.

Table 3. Linear Discrimination functions (LDF) and their environment of deposition for the study samples, after (Sahu, 1964).

\begin{tabular}{|c|c|c|c|c|c|c|c|c|}
\hline \multirow{2}{*}{ S.No. } & \multicolumn{2}{|r|}{ Y1 } & \multicolumn{2}{|r|}{ Y2 } & \multicolumn{2}{|r|}{ Y3 } & \multicolumn{2}{|r|}{ Y4 } \\
\hline & Value & Environment & Value & Environment & Value & Environment & Value & Environment \\
\hline A1 & -2.78 & Aeolian & 72.45 & Sh. agitated water & -3.71 & Sh. marine & 7.80 & Turbidity current \\
\hline A2 & -3.75 & Aeolian & 69.56 & Sh. agitated water & -0.32 & Sh. marine & 6.12 & Turbidit \\
\hline A3 & -5.34 & Aeolian & 76.37 & Sh. agitated water & -1.74 & Sh. marine & 8.71 & Turbidity current \\
\hline A4 & -3.79 & Aeolian & 78.62 & Sh. agitated water & -1.28 & Sh. marine & 8.17 & Turbidit \\
\hline A5 & -4.38 & Aeolian & 68.24 & Sh. agitated water & -0.15 & Sh. marine & 6.35 & Turbidity current \\
\hline A6 & -4.65 & Aeolian & 66.88 & Sh. agitated water & -0.09 & Sh. ma & 6.22 & Turbid \\
\hline A7 & -4.26 & Aeolian & 75.19 & Sh. agitated water & -1.01 & Sh. marine & 7.89 & Turbi \\
\hline A8 & -4.02 & Aeolian & 80.39 & Sh. agitated water & -1.55 & Sh. ma & 8.66 & Turbidity current \\
\hline A9 & -3.42 & Aeolian & 71.20 & Sh. agitated water & -2.88 & Sh. 1 & 5.21 & Turbic \\
\hline A10 & -4.03 & Aeolian & 81.67 & Sh. agitated water & -1.71 & Sh. & 8.81 & Turbi \\
\hline A11 & -4.03 & Aeolian & 71.63 & Sh. agit & -0.52 & Sh. & 6.76 & Turbi \\
\hline A12 & -3.25 & Aeolian & 70.71 & Sh. agitated water & -0.63 & Sh. marine & 5.58 & Turbidit \\
\hline A13 & -4.36 & Aeolian & 74.36 & Sh. agita & -0.94 & Sh. & 7.80 & Turbidity current \\
\hline A14 & -5.54 & Aeolian & 67.08 & Sh. agitated water & -0.74 & Sh. marine & 6.94 & Turbidity current \\
\hline A15 & -4.30 & Aeolian & 71.97 & Sh. agitated water & -0.61 & Sh. marine & 7.16 & Turbi \\
\hline A16 & -4.09 & Aeolian & 72.51 & Sh. agitated water & -0.63 & Sh. marine & 7.06 & Turbidity current \\
\hline A17 & -5.04 & Aeolian & 74.78 & Sh. agitated water & -1.44 & Sh. marine & 8.30 & Turbidity current \\
\hline A18 & -3.67 & Aeolian & 84.46 & Sh. agitated water & -1.93 & Sh. marine & 8.89 & Turbidity current \\
\hline A19 & -4.51 & Aeolian & 81.56 & Sh. agitated water & -1.92 & Sh. marine & 8.81 & Turbidity current \\
\hline B1 & -5.76 & Aeolian & 61.53 & Littoral (beach) & -0.11 & Sh. marine & 5.75 & Turbidity current \\
\hline
\end{tabular}




\begin{tabular}{|c|c|c|c|c|c|c|c|c|}
\hline B2 & -3.75 & Aeolian & 69.56 & Sh. agitated water & -0.32 & Sh. marine & 6.12 & current \\
\hline B3 & -5.39 & Aeolian & 74.79 & Sh. agitated water & -1.60 & Sh. marine & 8.56 & ity current \\
\hline B4 & -4.86 & Aeolian & 82.66 & Sh. agitated water & -2.25 & Sh. marine & 8.96 & Turbidity current \\
\hline B5 & -6.57 & Aeolian & 87.61 & Sh. agitated water & -3.41 & Sh. marine & 7.37 & Turbidity current \\
\hline B6 & -3.18 & Aeolian & 71.68 & Sh. agitated water & -0.97 & Sh. marine & 5.32 & urrent \\
\hline B8 & -5.33 & Aeolian & 76.40 & Sh. agitated water & -1.76 & Sh. marine & 8.65 & Turbidity current \\
\hline B9 & -5.08 & Aeolian & 64.33 & Littoral (beach) & -0.02 & Sh. marine & 6.01 & Turbidity current \\
\hline B 10 & -3.98 & Aeolian & 79.92 & Sh. agitated water & -1.48 & Sh. marine & 8.60 & Turbid \\
\hline B11 & -5.37 & Aeolian & 75.39 & Sh. agitated water & -1.66 & Sh. marine & 8.59 & rrent \\
\hline B12 & -5.33 & Aeolian & 74.78 & tated water & -1.64 & Sha. marine & 8.42 & Irrent \\
\hline B13 & -5.34 & Aeolian & 76.25 & Sh. agitated water & -1.74 & marine & 8.67 & Irrent \\
\hline B14 & -5.44 & Aeolian & 74.47 & Sh. agitated water & -1.54 & Sh. marine & 8.56 & rrent \\
\hline B15 & -5.91 & Aeolian & 65.71 & ted water & -0.80 & Sh. marine & 6.87 & rrent \\
\hline B16 & -4.32 & Aeolian & 68.46 & ted water & -0.19 & narine & 6.35 & urrent \\
\hline B17 & -5.32 & Aeolian & 76.58 & ed water & -1.78 & Sh. $n$ & 8.67 & rrent \\
\hline B18 & -5.37 & Aeolian & 74.93 & Sh. agitated water & -1.63 & Sh. marine & 8.52 & rrent \\
\hline B19 & -5.36 & Aeolian & 76.76 & ed water & -1.75 & arine & 8.79 & rrent \\
\hline $\mathrm{C} 1$ & -5.86 & Aeolian & 66.36 & Sh. agitated water & -0.88 & Sh. marine & 6.99 & rrent \\
\hline $\mathrm{C} 2$ & -3.92 & Aeolian & 69.36 & ted water & -0.30 & arine & 6.28 & rrent \\
\hline $\mathrm{C} 3$ & -5.64 & Aeolian & 85.99 & ted water & -2.97 & arine & 9.24 & rrent \\
\hline $\mathrm{C} 4$ & -5.32 & Aeolian & 79.08 & Sh. agitated water & -2.08 & Sh. marine & 8.82 & Turk \\
\hline $\mathrm{C} 5$ & -4.82 & Aeolian & 84.50 & ated water & -2.43 & Sh. & .05 & rrent \\
\hline C6 & -3.31 & Aeolian & 86.80 & itated water & -2.29 & Sh. marine & 8.65 & ty current \\
\hline C6 & -3.71 & Aeolian & 95.15 & Sh. agitated water & -3.41 & Sh. marine & 8.99 & y current \\
\hline $\mathrm{C} 8$ & -2.81 & Aeolian & 82.15 & Sh. agitated water & -2.56 & Sh. marine & 6.33 & ty current \\
\hline C9 & -3.43 & Aeolian & 81.42 & Sh. agitated water & -1.63 & Sh. marine & 8.24 & ty current \\
\hline $\mathrm{C} 10$ & -5.49 & Aeolian & 81.80 & Sh. agitated water & -2.41 & Sh. marine & 9.14 & y current \\
\hline $\mathrm{C} 11$ & -2.81 & Aeolian & 87.79 & Sh. agitated water & -2.36 & Sh. marine & 8.35 & Turbidity current \\
\hline $\mathrm{C} 12$ & -5.77 & Aeolian & 86.50 & Sh. agitated water & -3.05 & Sh. marine & 9.08 & ty current \\
\hline $\mathrm{C} 13$ & -5.66 & Aeolian & 84.03 & Sh. agitated water & -2.71 & Sh. marine & 9.21 & Turbidity current \\
\hline $\mathrm{C} 14$ & -5.47 & Aeolian & 71.56 & Sh. agitated water & -1.33 & Sh. marine & 7.93 & Turbidity current \\
\hline $\mathrm{C} 15$ & -5.16 & Aeolian & 66.29 & Sh. agitated water & -0.33 & Sh. marine & 6.46 & Turbidity current \\
\hline C16 & -5.36 & Aeolian & 76.54 & Sh. agitated water & -1.72 & Sh. marine & 8.79 & Turbidity current \\
\hline $\mathrm{C} 17$ & -5.57 & Aeolian & 71.19 & Sh. agitated water & -1.31 & Sh. marine & 7.94 & Turbidity current \\
\hline $\mathrm{C} 18$ & -5.95 & Aeolian & 88.51 & Sh. agitated water & -3.35 & Sh. marine & 8.99 & Turbidity current \\
\hline C19 & -5.35 & Aeolian & 77.45 & Sh. agitated water & -1.82 & Sh. marine & 8.80 & Turbidity current \\
\hline Avg. & -4.68 & Aeolian & 76.14 & Sh. agitated water & -1.56 & Sh. marine & 7.81 & Turbidity current \\
\hline
\end{tabular}

Note: sh. (shallow).

\section{Mode of transportation (C-M diagram)}

To delineate the mode of the transport of the investigated sediments along the area of study, the C-M diagram has been applied, after (Passega, 1964). This diagram is based on the $1 \%$ percentage (one percentile) representing the maximum grain size and indicating the competency of the transporting agent, while the $50 \%$ percentage (median) expresses the median grain size of sediment transported. The $\mathrm{C}$ and $\mathrm{M}$ values are presented in Microns given in Table 1.

The plotting study points show clustering on the $\mathrm{V}$ field which is denoted by $\mathrm{C}<$ 1000 Microns and $100<\mathrm{M}>200$ Microns and only two samples of profile A fall in the IV field indicating mainly traction current transport where suspended sediments are 
incorporated. The range of $\mathrm{C}$ points is (250 to 615) Microns with average of 355 Microns and the median points range are (148.49 to307) Microns with an average of 178 Microns.

\section{DISCUSSION}

Sand is the main sediment size observed in the investigated samples along the three beach profiles (A, B and C). The three profiles show unimodal distribution in nature with average peaks at $2.5 \Phi$, signifying fine sand mode, and a narrow range of sediment size, indicating the consistent depositional process and revealing a single provenance sediment source (Fig. 2). The normal curves of the three profiles display a predominant fine sand population mixed with varying subordinate populations (mainly medium sand; and very fine sand; fines subpopulations) that tend to be finer towards the backshore along profile $\mathrm{C}$ samples, where a small tail of silt is noticed. The dominance of fine grains is attributed to the Nile source nature of the sediment.

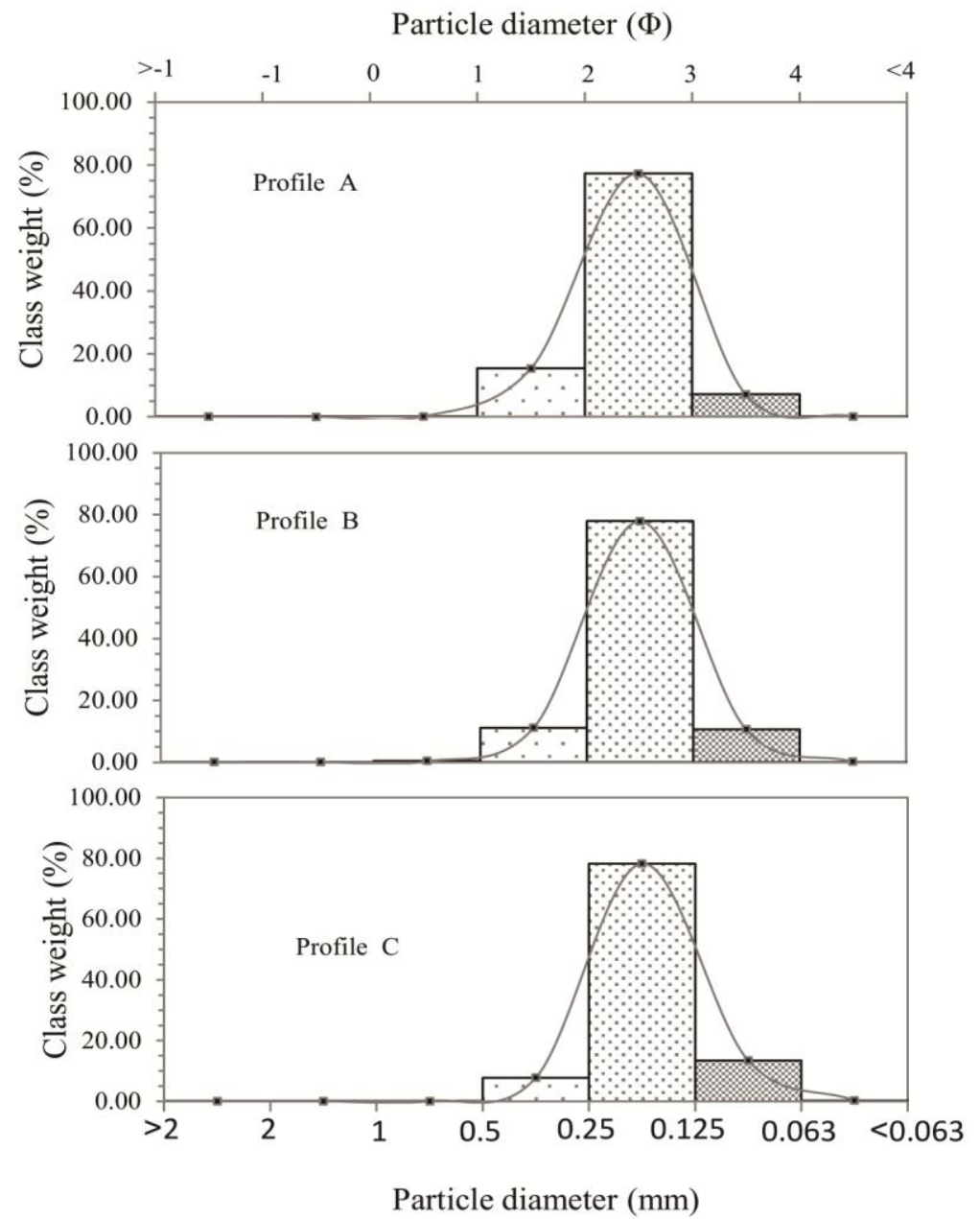

Fig. 2. Average frequency histograms and their normal curves of grain size distribution of samples along the three profiles (A, B, and C) parallel to the shoreline.

The slightly coarser trend towards the shoreline could be attributed to enrichment in shell fragments along the shoreline and removal of fine particles by the winnowing action of wave and current as proposed by (Mason and Folk, 1958; Friedman, 1961, 1962; Duane, 1964; Friedman, 1967).The operating processes on the study area controls the 
fines availability as these processes greatly affect the shoreline profile (profile A) resulting in the slight increase in coarse subpopulations relative to the fines subpopulations in an absence of riverine supply, indicating fines dispersal towards offshore while these processes diminish towards backshore. Profile B could be considered as a transitional zone where the coarse and the fines subpopulations are equally added, assuming that the available energy magnitude indicated by coarse subpopulations, and the availability of fines are in equilibrium state. At profile $\mathrm{C}$, the operating processes influence decrease and the fines subpopulations exceed the coarse ones, as the energy is insufficient to disperse the abundant fines (Singarasubramanian et al., 2006). Detectable deviations in the compositional formula of the sediment mixture along the three profiles occur although the prevailing unimodal distributions resulted from the type and amount of energy affects the depositional profiles that in turn, resulted in a great sensitivity in the grain size parameters distribution.

The sediment mean size $\left(\mathrm{M}_{\mathrm{z}}\right)$ values are represented in Fig. 3a, and Fig. 4a. The coarsest mean value placed at the most west sample of Rosetta mouth could be attributed to the contribution impacts of fishing and guard station activities. Sample site A9 shows value of 2.01Ф (fine sand) which is slightly different among the mean values located east of Rosetta mouth where it is attributed to its location on the updrift side of the coastal structures (groins) where the coarse eroded sediment tend to build around the structures . Generally, the eastern area of Rosetta mouth tend to be finer in mean size than the western area due to littoral drift influence that carry the discharged sediments towards east of the Rosetta mouth. The calculated mean values for the three profiles point to gradual increase in mean values towards profile $\mathrm{C}$ samples indicating a fining grain size train towards inland.

In general, the inclusive graphic standard deviation values fluctuate between moderately well-sorted to well-sorted sediments along the three profiles of the study area suggesting a high energy environment, referred to the back and forth motion of the sediments through the continuous reworking action of beach ridges and screening process of waves (during the heavy tidal wave), and currents. The sorting $\left(\sigma_{\mathrm{I}}\right)$ values are represented in Fig. 3b, and Fig. 4b.

Profile B exhibits most well-sorted sediments owing to the near contributions of its sub-populations with the predominant one while the moderately well-sorted nature increases towards both the directions of profile $\mathrm{A}$ and profile $\mathrm{C}$ that resulted from the intermixing of different fractions and in varying proportions. The moderately well-sorted nature is attributed to the addition of coarse fractions and removal of fines through the reworking of beach at profile $\mathrm{A}$ and attributed to the addition of fines sediment from the riverine input and aeolian processes or the relatively remoteness location from the action of waves and current at profile $\mathrm{C}$.

Skewness $\left(\mathrm{Sk}_{\mathrm{I}}\right)$ values along the three profiles vary from coarse skewed to fine skewed fields, indicating the prevalence of mixed energy environment corresponding to different localities. The skewness values are represented in in Fig. 3c, and Fig. 4c.

The prevailed negative skewness of profile A proposed to be corresponding to high energy condition and winnowing of the sediments, resulting from removal of fines particles by the persistent wave and current action. The near symmetrical nature zones along profile $\mathrm{A}$ is attributed to the absence of extreme conditions like tidal variations, wave breaking and seasonal supply of detrital materials (Selvaraj and Mohan, 2003) 
where the fine skewed zones in the same profile A are resulted in such high energy environment indicates excessive riverine inputs. The positively skewness nature that dominated profile $\mathrm{B}$ followed by profile $\mathrm{C}$, reflects that the area is dominated by unidirectional transport (channel) or relatively low energy conditions resulted in accumulation of finer sediments. Unlikely, the zones characterized by negative skewed values along profile $\mathrm{B}$ and $\mathrm{C}$ indicated removal of the fine sediments by erosion.

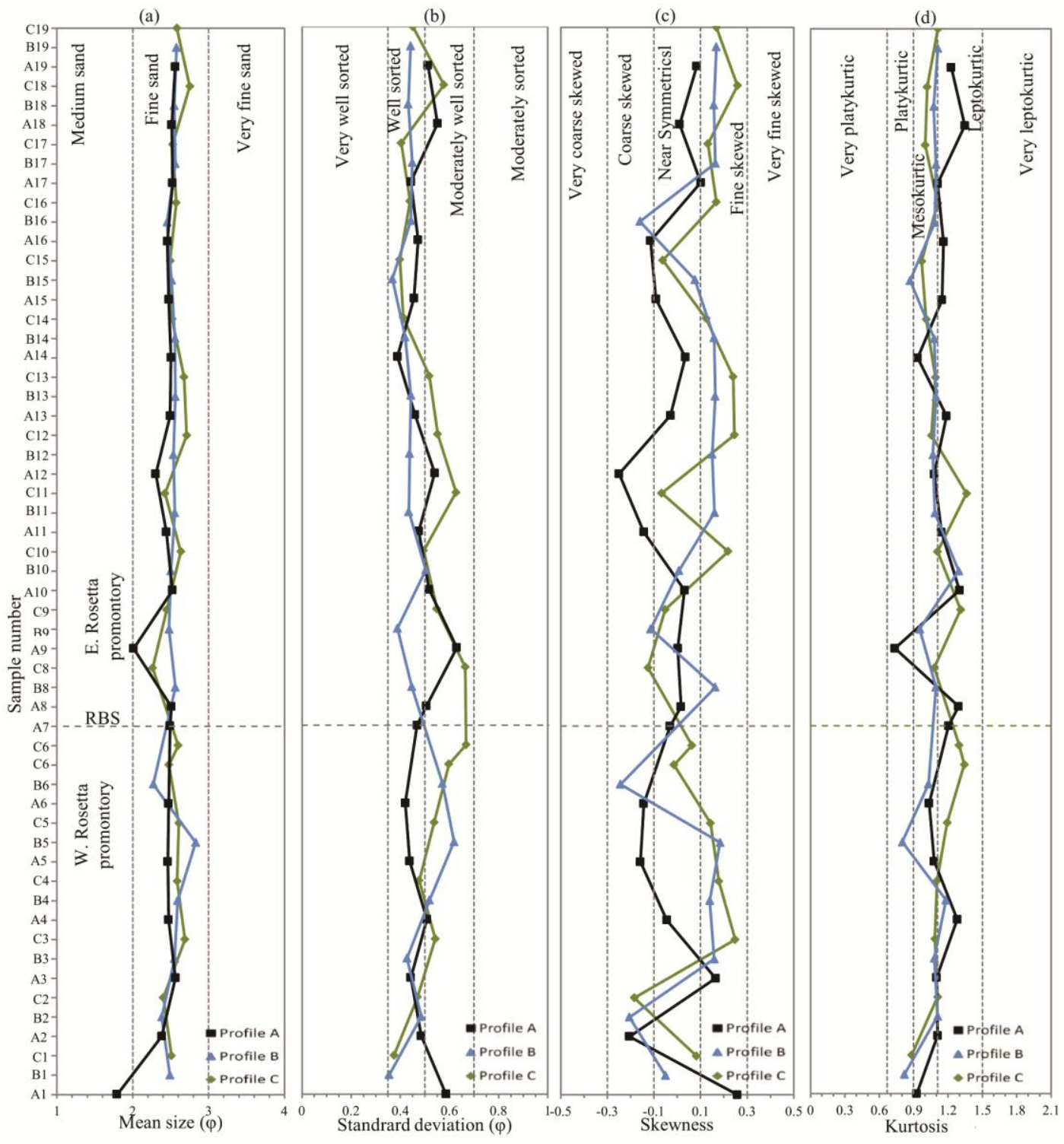

Fig. 3. Statistical parameters of the grain size distribution along the profiles samples of the study area (A, $\mathrm{B}$, and $\mathrm{C}$ profiles).

The leptokurtic to platykurtic nature indicated multiple environments processing prevailing along the coast variegates from riverine/aeolian environment to marine environment. The variation in the kurtosis values is a reflection of the flow characteristic of the depositional medium (Ray et al., 2006). Kurtosis values are represented in in Fig. 3d, and Fig. 4d. 
The dominance of leptokurtic nature in profile $\mathrm{A}$ is due to the maximal energy action and the mesokurtic nature in profile $\mathrm{B}$ and $\mathrm{C}$, could be related to the minimal action of high energy factor resulting in continuous supply (stream) of finer sediment materials in variable amounts. Whilst the highest mesokurtic character in profile B is due to the analogous addition of both medium and very fine fractions. This predominality mesokurtic to leptokurtic nature of the three profiles refers to the unimodal nature of sediments and the energy fluctuations of the depositional medium.
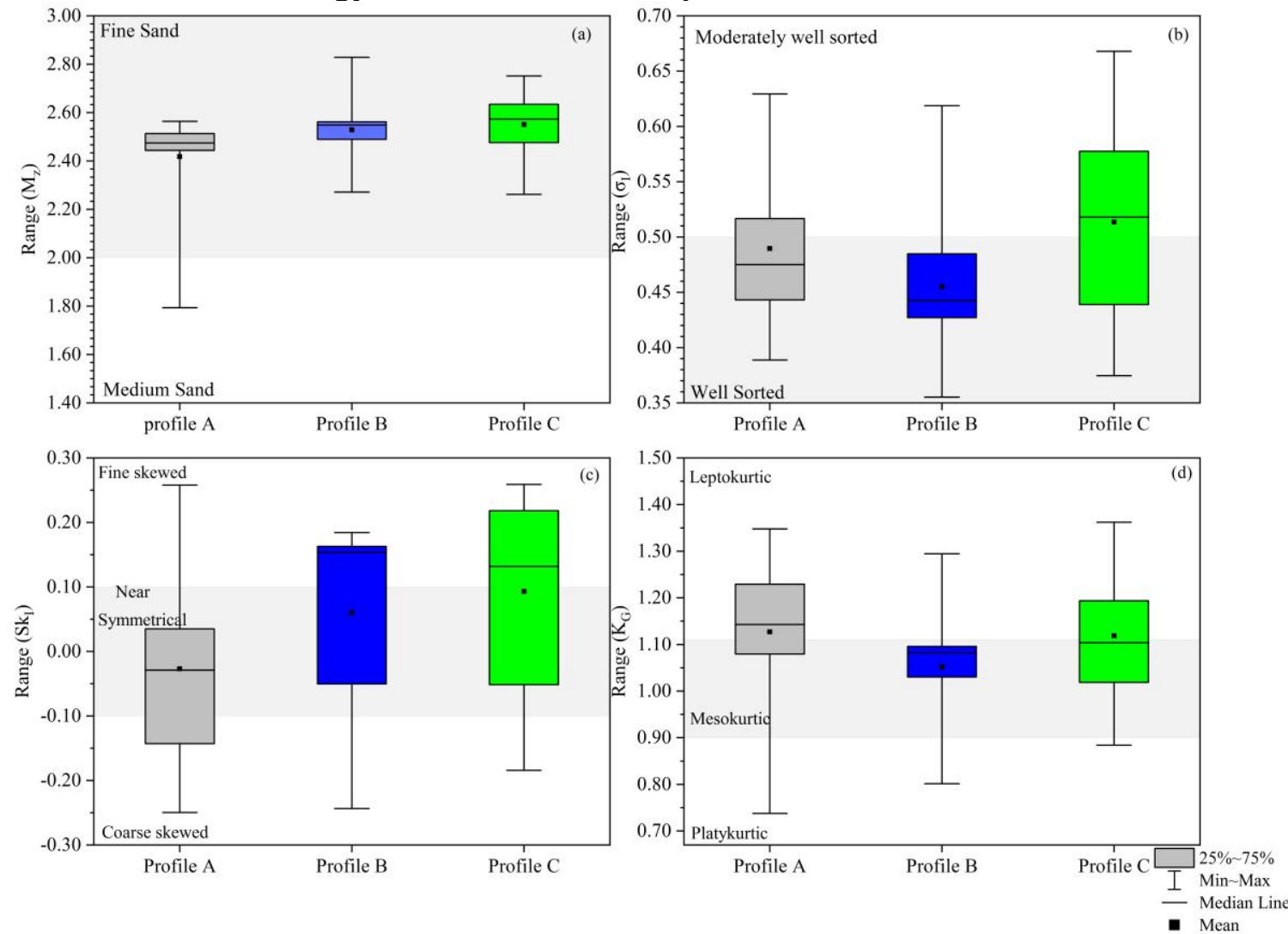

Fig. 4. Box plots of: (a) mean size $\left(\mathrm{M}_{\mathrm{z}}\right)$, (b) standard deviation $\left(\sigma_{\mathrm{I}}\right)$, (c) skewness $\left(\mathrm{Sk}_{\mathrm{I}}\right)$, (d) kurtosis $\left(\mathrm{K}_{\mathrm{G}}\right)$ of the studied samples.

It is worth mentioning that fine sand size, well sorted nature, and near symmetrical character of skewness and leptokurtic nature of kurtosis distribution of river bed sample greatly reflects the depositional environment and energy conditions as its locality in the opening mouth of the river. Its grain size distribution resembles in its characteristics the shoreline samples indicating excess of coarse sub-populations from the fishing cages and relatively a high energy environment where the wave energy and the river current energy act.

\section{Depositional Environment}

Bivariate plots of the four statistical grain size parameters represent tools to identify mechanisms of sediment transportation and depositional settings (Sutherland and Lee, 1994).

The bivariate plot of mean size versus standard deviation (sorting), shows a narrow range of moderately well-sorted to well-sorted of the fine sediment size range, (Fig. 5a). This distribution indicated a unimodal-source of fine grain size sediment samples (Griffith, 1967). The fine-grained sediment nature signifies the long transport time 
resulted into grain to grain interaction reducing the grain sizes. The predominance of moderately well-sorted to well-sorted sediments indicates continuous reworking of the sediments by currents and waves (Griffith, 1967).

The scatter plot revealed that sorting is rather a closely controlled V shaped of the mean size, referred to the reflection point which is the mode of sediments $(2.50 \Phi)$ where, most of profile A's values fall left to the mode value meanwhile profile $\mathrm{B}$ and profile $\mathrm{C}$ values cluster right. The fining sequence characterizes the backshore direction, corresponding to the river-input of very fine classes and farness from the energy reworking.
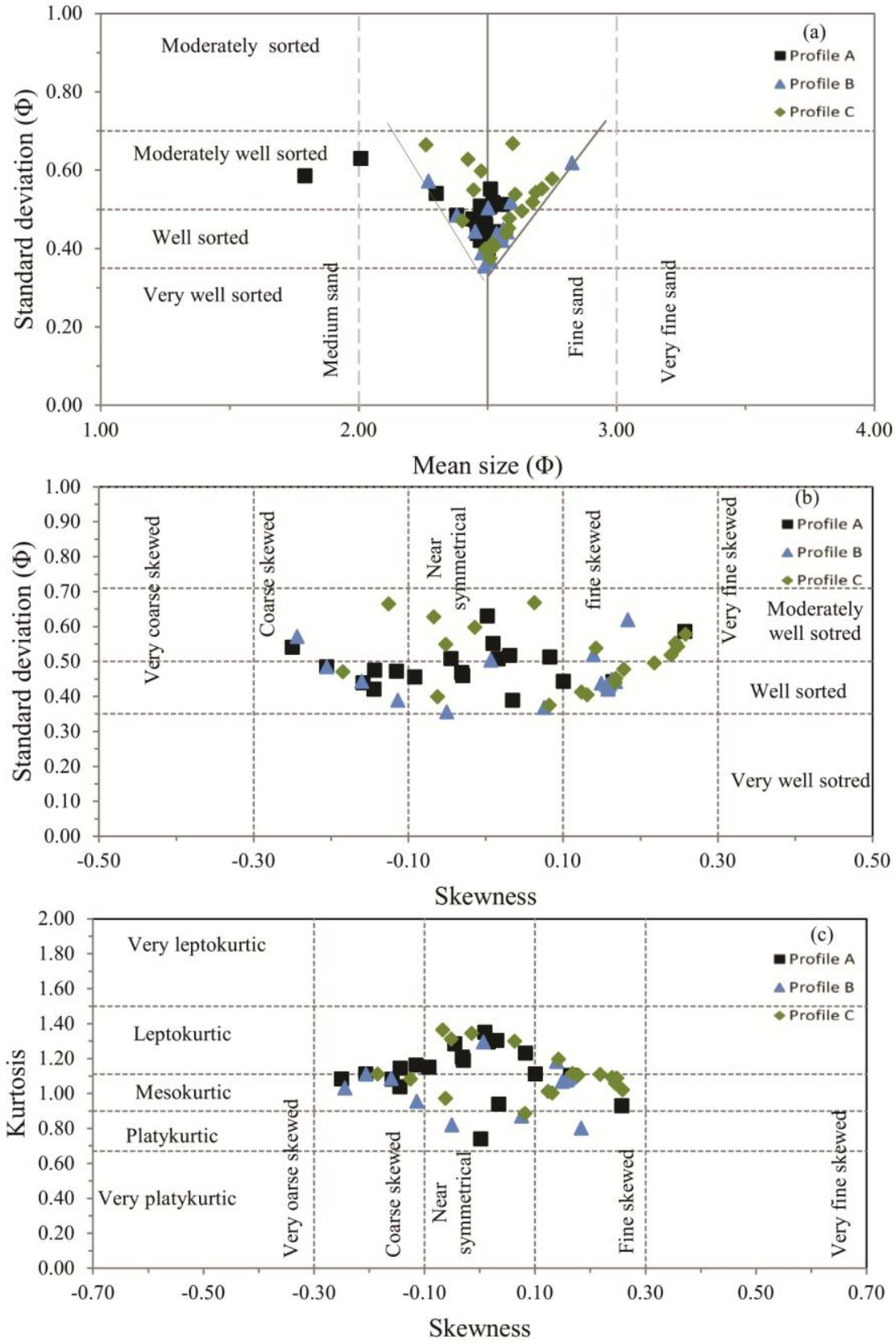

Fig. 5. Bivariate cross plots between (a) mean size and sorting, (b) skewness and sorting, (c) skewness and kurtosis. 
Although the discharge of the Nile River sediments is dramatically decreased, the riverine sediments are still predominate, while marine signature marks the distribution. As the moderately-well sorted to well-sorted nature prevails in a function of the energy condition; this proved that sedimentation has been taken place due to both river influence and beach process. The action of wave-driven longshore currents followed the sand delivery and continued to transport beach sediments of the eroded beach samples to the east. It is concluded that the sedimentary environments along the study area is mainly hydraulically controlled, denoted from the recorded well-sorted and fine grain sediments.

The standard deviation (sorting) versus skewness bivariate plot showed that, at profile A, the sediments are characterized by a negatively skewed and well-sorted nature, indicating the marine signature, along the shoreline area (Fig. 5b). The sediments at profile $\mathrm{B}$ exhibit the most positively skewed values with well-sorted nature, while at profile $\mathrm{C}$; they are positively skewed with moderately well-sorted trend. The highest well sorting values and the positive skewed values are recorded along profile $\mathrm{B}$, with decreasing trend towards both directions (profile $\mathrm{A}$ and profile $\mathrm{C}$ ). It is concluded that profile B showed a turning point trend, between the marine signature, (represented by profile $\mathrm{A}$ ), and the riverine/aeolian signature, (represented by profile $\mathrm{C}$ ), leading to formation of a common mixing zone. This conclusion is consistent with the beach environment, characterized by repetition of summer cycle and winter cycle (Komar, 1976; Ding et al., 2001). During the winter cycle, most of the beach face is covered by sea water shifting sediments from offshore to form series of sand bars; while in summer cycle, the sediments return offshore.

Plotting of skewness versus kurtosis assists interpreting the genesis of sediment, depending on the degree of normality of its size distribution (Folk, 1966). Generally, the plot shows the relatively dominance of mesokurtic to leptokurtic range, and very limited number of samples is platykurtic in the fine size class, suggesting the mixing of different subordinate grain size populations, with the predominant fine-grained size population (Fig. 5c). The majority of the samples at profile A is located near symmetrical samples and points out to leptokurtic nature reflecting shoreline characters. Mesokurtic values relatively dominate towards the backshore within profile $\mathrm{B}$ and $\mathrm{C}$. Profile $\mathrm{B}$ values are the highest $(72.2 \%)$ for positive skewness and $(61.1 \%)$ for mesokurtic nature while the values are decreasing towards profile A (47.4\%) for positive skewness and (36.8\%) for mesokurtic nature and also decrease towards profile $\mathrm{C}(68.4 \%)$ for positive skewness and $(52.6 \%)$ for mesokurtic nature. This distribution confirms the transition of mixing features of profile B driven by the influence of marine processes (profile A) and riverine/aeolian processes (profile $\mathrm{C}$ ).

\section{Discrimination of Environmental Boundaries}

A plot of skewness vs standard deviation is the most effective in differentiating between river and beach sands (Friedman, 1967), while (Moiola and Weiser, 1968) pointed out, that the plot of mean size vs standard deviation is used for discriminating beach and river sands.

Fig. 6a of mean size and standard deviation reveal that the beach environment is the samples environment deposition according to (Friedman, 1967) boundary. The Fluvial influence is evident from the abundance of fine grain size, while beach environment is evident from the better sorting character, driven by the energy wave motion on beaches. Accordingly, beach environment near a river mouth is predominant as a deltaic outcome. 
(Moiola and Weiser, 1968) documented that the coastal dune environment is predominate over the river and beach environments attributed to both the better sorting and the fine grain size of the sand sediments.
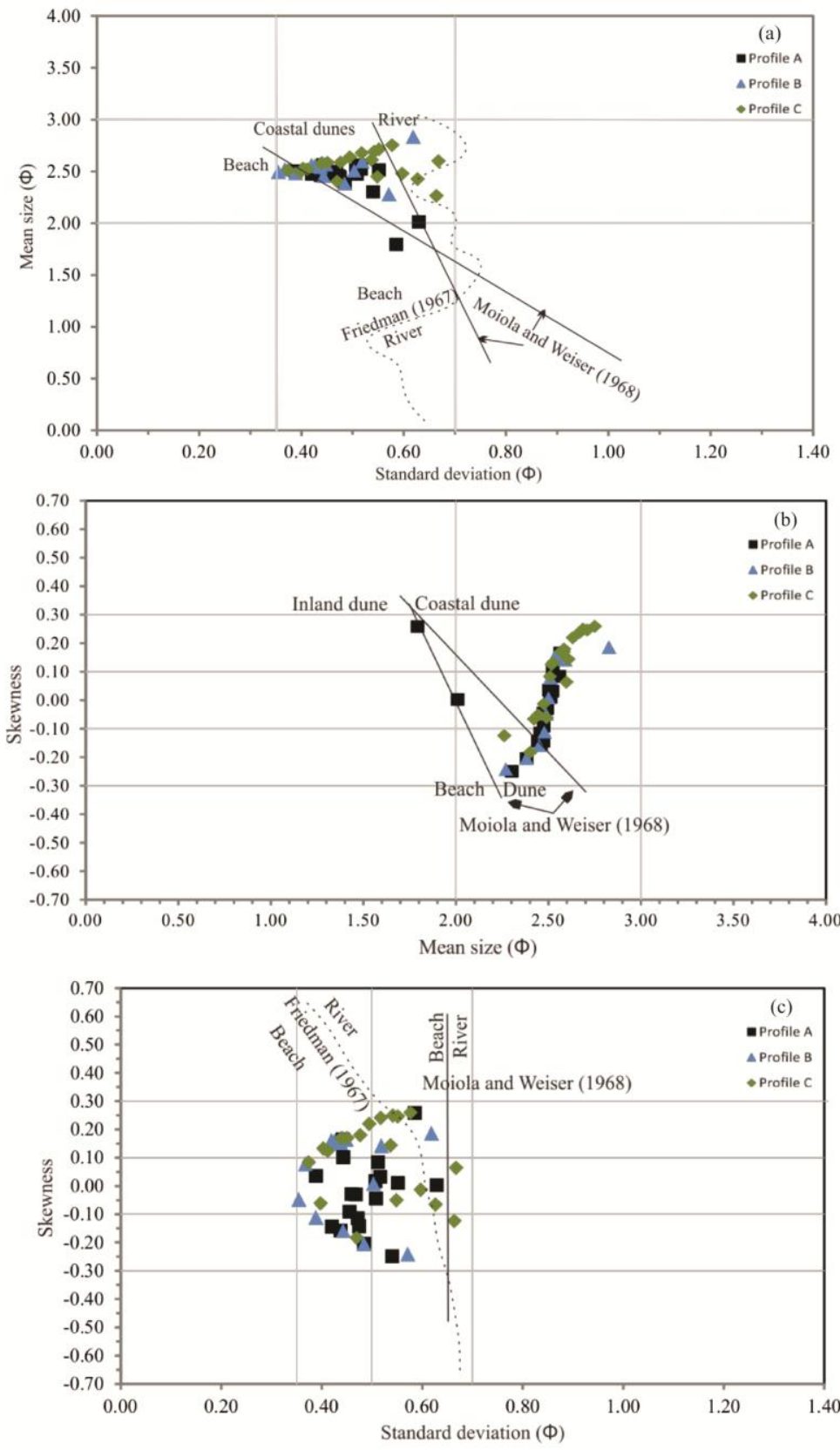

Fig. 6. Correlation of scatter plot with discriminating environmental boundaries, after (Friedman, 1967; Moiola and Weiser, 1968) between (a) standard deviation versus mean size. (b) mean size versus skewness (c): standard deviation versus skewness.

The correlation of bivariate plot of mean size vs skewness with discriminating environmental boundaries, (Fig. 6b), indicates that, the coastal dune environment is the environment of deposition according to (Moiola and Weiser, 1968), attributed to both the fine size diameter and the restricted range of positive to negative skewness. Correlation plot of standard deviation versus skewness after both boundaries of 
(Friedman, 1967; Moiola and Weiser, 1968), (Fig. 6c) coincides that beach environment is the prime depositional environment where this relation could be the well suited for separation of the study deposits.

These plots indicate the sedimentation trends of such special deltaic environments where river and beach environments are participating for the sedimentation process and where the time and space factor can favor one environment over the other. Thus, these plots should be dependent on the both the relation between the enclosing two parameters taking into the consideration the special environments where two or more contributions are involved, the effects of regional variations in grain size, climate sedimentation energy, and relative energy conditions within the final environments (Amaral and Pryor, 1977).

\section{Energy and Hydrodynamic Conditions}

Based on the cross correlation between Y1, and Y2 values, the sediments are distributed in the aeolian process based on Y1 values where the energy fluctuations are least and the sediments are best sorted and within shallow agitated water based on Y2 values (Fig. 7). Shallow marine water is proposed upon Y3 values as the wave action is less prominent and more variable and the sediments are less uniformly distributed. Turbidity action is a turbulence deposited energy based on Y4 values, characterized by energy fluctuations and variation in the fluidity factor.
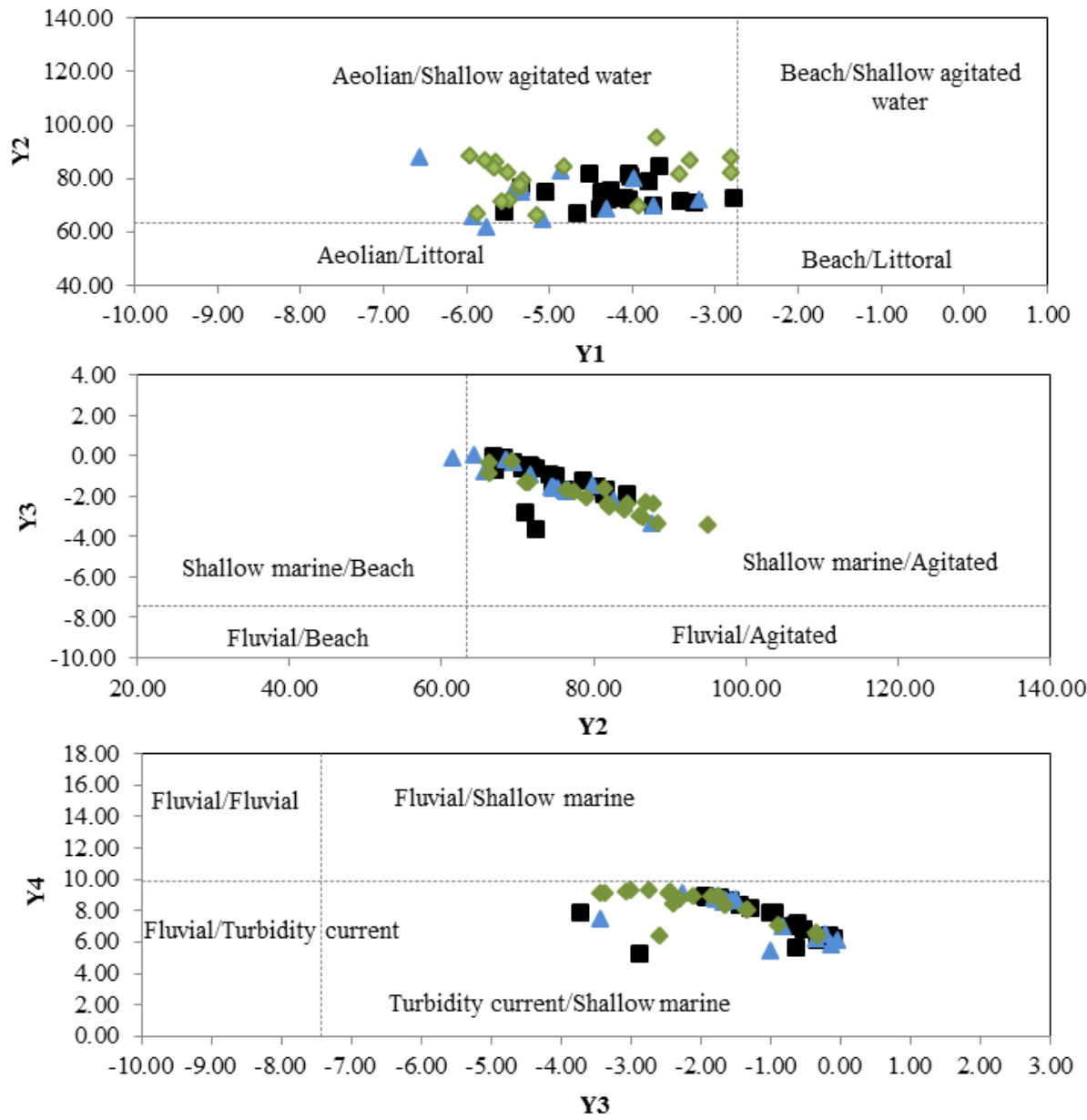

Fig. 7. Discrimination of environments based on Linear Discrimination functions (LDF) plot, after (Sahu, 1964). 
The LDF analyses were succeeded in delineating the process and environment of deposition. Consequently, the studied sediments over Rosetta area have fluvial nature, evident from their grain size distributions, deposited by turbidity current action, within shallow agitated marine environment.

Discrimination of the energy processes along the study area is revealed from the graphic plots of median size versus both standard deviation and skewness (Fig. 8). This correlation is originally suggested by (Stewart, 1958). According to the energy process diagram, the area of study is restricted within the wave energy pattern field, concluding that the active energy process of marine environment is the main regulator of depositional process.
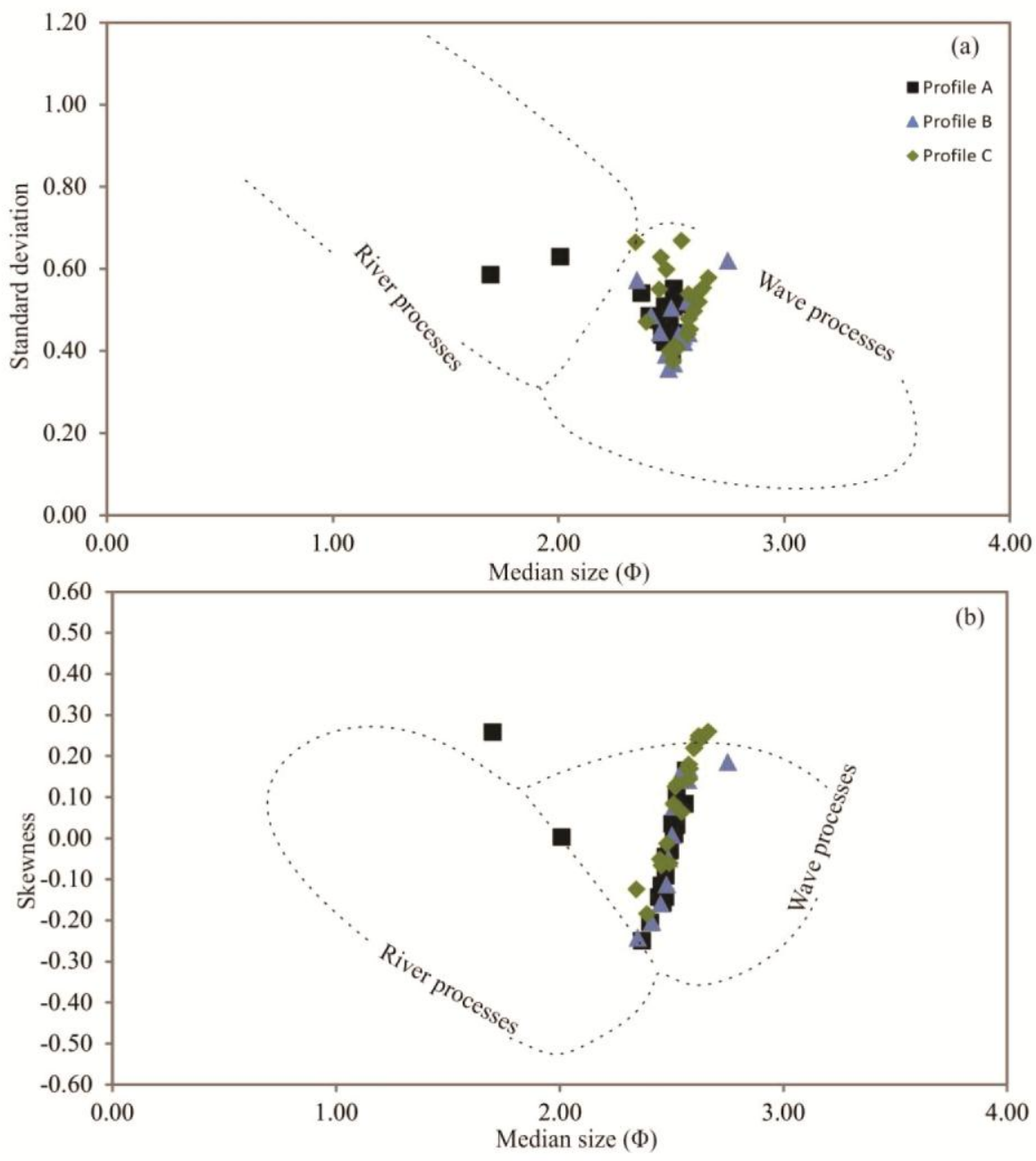

Fig. 8. Energy process diagram for the study sediment samples showing the relationships between (a) median size vs standard deviation (b) median size vs skewness, after (Stewart, 1958).

The use of a powerful relation between skewness and kurtosis is a means to provide a sediment/energy relationship that is best relevant to express the sedimentary processes in all lacustrine and marine environments in which materials are of detrital origin (Sly, 1978). The study sediments fit components " $\mathrm{E}-\mathrm{H}$ " submitting a high energy environment of deposition (Fig. 9). 


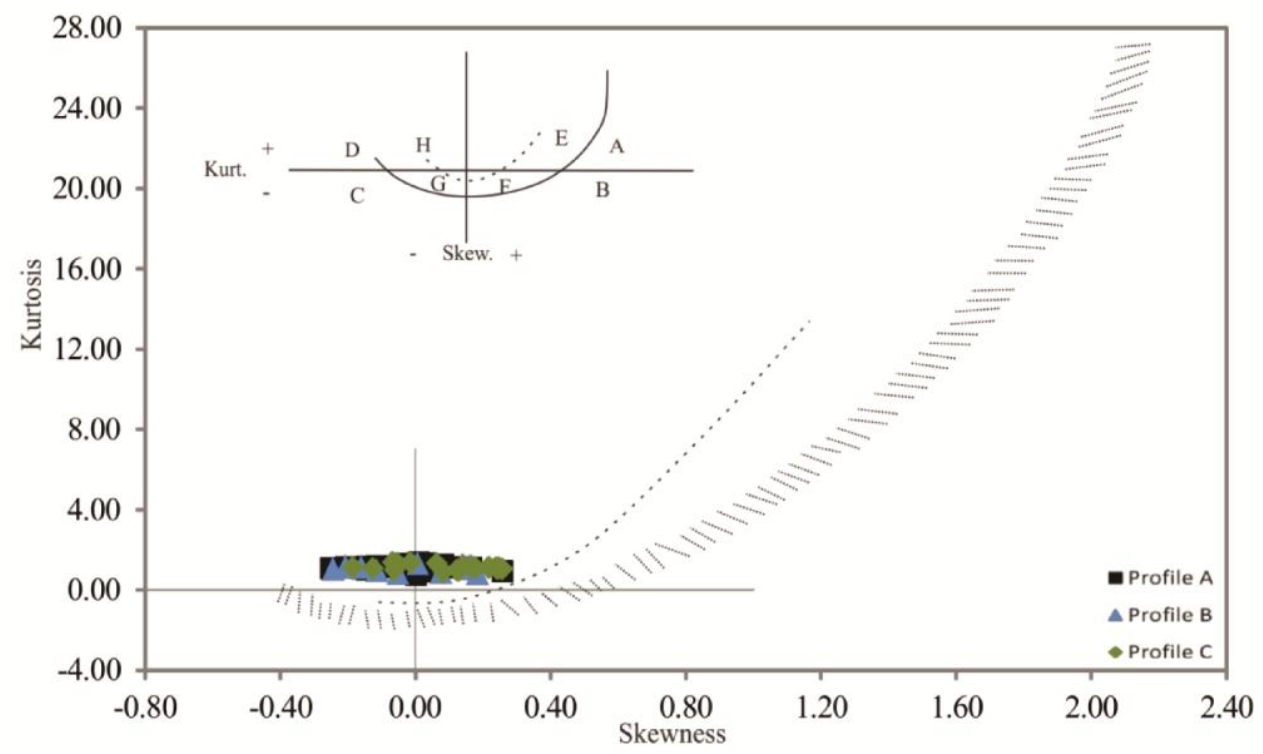

Fig. 9. Skewness and kurtosis relationship for the study samples, after (Sly, 1978).

\section{Mode of Transportation}

The sediments are generally considered as a mixture of two to three log-normal subpopulations, produced chiefly by three modes of transportation, (rolling "surface creep", saltation and true suspension mode), where a single sample may contain all the three modes. The coarser particles are transported by rolling, grain size of lower range is carried by saltation, and meanwhile the fine particles are carried in true suspension (Passega, 1964). The suspension sediments $(<2.5 \Phi)$ are inferred to be fine in character and show better sorting and their deposition mainly driven by bottom tractive current, like river, marine currents, and waves touching bottom.

The plot points fall in-between Cs: the maximum limit diameter of graded suspension; transported grains through saltation and $\mathrm{Cu}$ : the maximum limit of uniform suspension; transported grains in the upper water column part (Fig. 10). The samples points are mostly clustered in the QR segment of graded suspension of tractive current transport deposits and few points fall in the PQ segment. Clustering is imported due to the lack of difference in the hydrodynamic regimes prevailing in the area. PQ segment indicates graded suspension grains mixed with rolled grains where rolling add a tail of small amount of coarse grains that affect $C$ value without changing $M$ value. $Q R$ segment signifies the graded suspension deposits where its plot values are roughly parallel to the $\mathrm{C}=\mathrm{M}$ limit and $\mathrm{V}$ values are roughly proportional to $\mathrm{M}$, so that for any value of $\mathrm{M}, \mathrm{C}$ is defined within narrow limits. The clustering of plot values near the $\mathrm{C}=\mathrm{M}$ line indicates best sorting, at least in their coarser half fraction.

The $\mathrm{C}-\mathrm{M}$ diagram succeeded in delineating the mode of the transport of sediments which is the tractive current of a river environment (Nile River) where the sediment mainly exhibits the graded suspension and suspension with rolling mode (saltation) as the prime factors for transportation where saltation mode is generally considered to be the product of graded suspension (Passega, 1964). The slightly vertical and horizontal change in $\mathrm{C}$ values causes transportation mechanism overlap that may be referred to varying in grain size, gravity of these grains, influenced mainly by current and wave activity turbulence, (marine energy fluctuations), in addition to the wind action influence. 


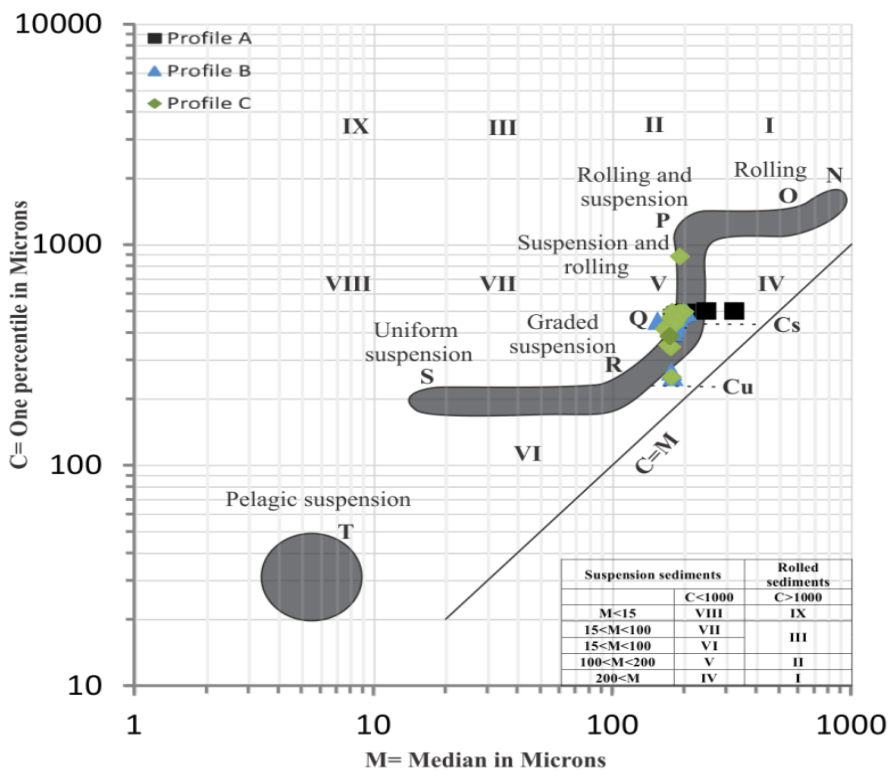

Fig. 10. C-M diagram showing the mode of transportation between $C$, (one percentile in Microns) and $M$ (median size in microns) after (Passega, 1957, 1964; Passega and Byramjee, 1969).

\section{CONCLUSION}

The grain size distribution of sediments along the three profiles revealed the dominance of unimodal fine sand sediments with a value of $2.5 \Phi$, represent the distribution of the pure sand, mainly Nile sand sources, indicating a consistent depositional process along the study area. The predominance of fine sand population mode mixed with varying subordinate populations tends to be fine towards the backshore, where a small tail of silt is observed. The slightly coarser trend towards shoreline could be attributed to enrichment in shell fragments along the shoreline and removal of fine particles by the winnowing action of waves and currents in an absence of riverine supply. Generally, the eastern area of Rosetta mouth tends to be more fine than the western area, due to littoral drift of current influence that carry the discharged sediments towards east of the Rosetta mouth.

The shoreline sediments along profile A are dominated by moderately well-sorted, mostly negative skewness values and leptokurtic nature of sediments, suggesting a high energy environment, through the continuous reworking action of beach ridges and screening process of waves and currents. The backshore dry area along profile $\mathrm{C}$ is characterized mainly by moderately well sorted, positive skewness values and mesokurtic nature corresponding to riverine/aeolian input within an unidirectional transport, controlled by relatively low energy condition compared to the shoreline, and resulted in accumulation of finer sediments that originally built up sand promontories on the delta faces. The semi-wet areas along profile B that represent intermediate area between shoreline and backshore area, has a common trend along the study area of most wellsorted nature, most positive skewness values and most mesokurtic nature attributed to the equal intermixing of the subordinate population with the predominant sediment mode and explained as a function of energy conditions sediments from marine and riverine/aeolian processing's. 
The predominance of well-sorted fine sand with near symmetrical character of skewness and leptokurtic nature of kurtosis distribution of river bed sample corresponds to the unidirectional river supply and transport (channel), besides the local impact of the depositional environment and relatively high energy condition that linked to the active Rosetta mouth environment and the fishing cages activity.

The study shows the great sensitivity of grain size parameters to the small changes in the compositional formula of the sediment mixture. Both the graded suspension and suspension with rolling mode (saltation) are the prime factors for transportation, where the sediments deposited and reworked by turbidity and marine actions, within a shallow agitated marine environment.

\section{Acknowledgments}

The authors would like to thank Dr. E.M. Deghidy from Marine Geology lab., National Institute of Oceanography and Fisheries (NIOF) for all his assistance and guidance and Mr. Hamada Hawash, and Mr. Ahmed Sabry, National Institute of Oceanography and Fisheries for all their assistance in conducting the sampling survey.

\section{REFERENCES}

Amaral, E. J. and Pryor, W. A. (1977). Depositional environment of the St. Peter sandstone deduced by textural analysis. Journal of Sedimentary Research, 47(1): 32-52. Doi:10.1306/212f70ea-2b24-11d7-8648000102c1865d

Blott, S. J. and Pye, K. (2001). GRADISTAT: a grain size distribution and statistics package for the analysis of unconsolidated sediments. Earth surface processes and Landforms, 26(11): 1237-1248. Doi:10.1002/esp.261

Boggs Jr., S. (2009). Petrology of sedimentary rocks. Cambridge university press, 600pp. Doi:10.1017/cbo9780511626487

Ding, Z. L.; Yu, Z. W.; Yang, S. L.; Sun, J. M.; Xiong, S. F. and Liu, T. S. (2001). Coeval changes in grain size and sedimentation rate of aeolian loess, the Chinese Loess Plateau. Geophysical Research Letters, 28(10): 2097-2100. Doi:10.1029/2000GL006110

Duane, D. B. (1964). Significance of skewness in recent sediments, western Pamlico Sound, North Carolina. Journal of Sedimentary Research, 34(4): 864-874. Doi:10.1306/74d711b8-2b21-11d7-8648000102c1865d

Fanos, A. M.; Khafagy, A. A. and Dean, R. G. (1995). Protective works on the Nile Delta coast. Journal of Coastal Research, 11(2): 516-528.

Folk, R. L. (1966). A review of grain-size parameters. Sedimentology, 6(2): 73-93. Doi:10.1111/j.1365-3091.1966.tb01572.x

Folk, R. L. and Ward, W. C. (1957). Brazos River bar [Texas]; a study in the significance of grain size parameters. Journal of Sedimentary Research, 27(1): 326. Doi:10.1306/74d70646-2b21-11d7-8648000102c1865d

Friedman, G. M. (1961). Distinction between dune, beach, and river sands from their textural characteristics. Journal of Sedimentary Research, 31(4): 514-529. Doi:10.1306/74D70BCD-2B21-11D7-8648000102C1865D

Friedman, G. M. (1962). On sorting, sorting coefficients, and the lognormality of the grain-size distribution of sandstones. The Journal of Geology, 70(6): 737-753. Doi:10.1086/jg.70.6.30066373 
Friedman, G. M. (1967). Dynamic processes and statistical parameters compared for size frequency distribution of beach and river sands. Journal of Sedimentary Research, 37(2): 327-354. Doi:10.1306/74d716cc-2b21-11d78648000102c1865d

Frihy, O. E. (2007). The Nile Delta: processes of heavy mineral sorting and depositional patterns. Developments in Sedimentology, 58: 49-74. Doi:10.1016/S00704571(07)58002-7

Frihy, O. E. (2017). Evaluation of future land-use planning initiatives to shoreline stability of Egypt's northern Nile delta. Arabian Journal of Geosciences, 10(5): 109. Doi:10.1007/s12517-017-2893-4

Frihy, O. E. and Komar, P. D. (1993). Long-term shoreline changes and the concentration of heavy minerals in beach sands of the Nile Delta, Egypt. Marine Geology, 115(3-4): 253-261. Doi:10.1016/0025-3227(93)90054-Y

Frihy, O. E.; Lotfy, M. F. and Komar, P. D. (1995). Spatial variations in heavy minerals and patterns of sediment sorting along the Nile Delta, Egypt. Sedimentary Geology, 97(1-2): 33-41. Doi:10.1016/0037-0738(94)00135-H

Frihy, O. E. and Dewidar, K. M. (2003). Patterns of erosion/sedimentation, heavy mineral concentration and grain size to interpret boundaries of littoral sub-cells of the Nile Delta, Egypt. Marine Geology, 199(1-2): 27-43.

Ghoneim, E.; Mashaly, J.; Gamble, D.; Halls, J., and AbuBakr, M. (2015). Nile Delta exhibited a spatial reversal in the rates of shoreline retreat on the Rosetta promontory comparing pre-and post-beach protection. Geomorphology, 228: 1-14. Doi:10.1016/j.geomorph.2014.08.021

Goldsmith, V. and Golik, A. (1980). Sediment transport model of the southeastern Mediterranean coast. Marine Geology, 37(1-2): 147-175. Doi:10.1016/00253227(80)90015-8

Griffith, J.C. (1967). Scientific Methods in Analysis of Sediments. New York (McGrawHill), 508pp.

Hamouda, A.; El-Gharabawy, S.; Awad, M.; Shata, M. and Badawi, A. (2014). Characteristic properties of seabed fluvial-marine sediments in front of Damietta promontory, Nile Delta, Egypt. The Egyptian Journal of Aquatic Research, 40(4): 373-383. Doi:10.1016/j.ejar.2014.11.006

Hereher, M. E. (2010). Vulnerability of the Nile Delta to sea level rise: an assessment using remote sensing. Geomatics, Natural Hazards and Risk, 1(4): 315-321. Doi:10.1080/19475705.2010.516912

Inman, D. L. and Jenkins, S. A. (1984). The Nile littoral cell and man's impact on the coastal zone of the southeastern Mediterranean. Proceedings of 19th International Conference on Coastal Engineering, American Society of Civil Engineers, 16001617pp. Doi:10.9753/icce.v19.109

Komar, P.D. (1976). Beach processes and sedimentation. Prentice-Hall, New York, 1, 429pp.

Marriner, N.; Flaux, C.; Morhange, C. and Kaniewski, D. (2012). Nile Delta's sinking past: Quantifiable links with Holocene compaction and climate-driven changes in sediment supply?. Geology, 40(12): 1083-1086. Doi:10.1130/G33209.1

Mason, C. C. and Folk, R. L. (1958). Differentiation of beach, dune, and aeolian flat environments by size analysis, Mustang Island, Texas. Journal of Sedimentary Research, 28(2): 211-226. Doi:10.1306/74d707b3-2b21-11d7-8648000102c1865d 
Moiola, R. J. and Weiser, D. (1968). Textural parameters; an evaluation. Journal of Sedimentary Research, 38(1): 45-53. Doi:10.1306/74d71ad2-2b21-11d7$8648000102 \mathrm{c} 1865 \mathrm{~d}$

Passega, R. (1957). Texture as characteristic of clastic deposition. AAPG Bulletin, 41(9): 1952-1984. Doi:10.1306/0BDA594E-16BD-11D7-8645000102C1865D

Passega, R. (1964). Grain size representation by CM patterns as a geologic tool. Journal of Sedimentary Research, 34(4): 830-847. Doi:10.1306/74D711A4-2B21-11D7$8648000102 \mathrm{C} 1865 \mathrm{D}$

Passega, R. and Byramjee, R. (1969). Grain-size image of clastic deposits. Sedimentology, 13(3-4): 233-252. Doi:10.1111/j.1365-3091.1969.tb00171.x

Ray, A. K.; Tripathy, S. C.; Patra, S. and Sarma, V. V. (2006). Assessment of Godavari estuarine mangrove ecosystem through trace metal studies. Environment International, 32(2): 219-223. Doi:10.1016/j.envint.2005.08.014

Sahu, B. K. (1964). Depositional mechanisms from the size analysis of clastic sediments. Journal of Sedimentary Research, 34(1): 73-83. Doi:10.1306/74D70FCE-2B2111D7-8648000102C1865D

Said, R. (1993). The River Nile: geology, hydrology and utilization. New York, Pergamon Press, 320pp. Doi:10.1016/C2009-0-11234-5

Selvaraj, K. and Mohan, V. R. (2003). Textural variation and depositional environments of innershelf sediments, off Kalpakkam, southeast coast of India. Journal-Geological Society of India, 61(4): 449-462. Doi:10.1007/s11707-0120330-2

Singarasubramanian, S. R.; Mukesh, M. V.; Manoharan, K.; Murugan, S.; Bakkiaraj, D.; John Peter, A. and Seralathan, P. (2006). Sediment characteristics of the M-9 tsunami event between Rameswaram and Thoothukudi, Gulf of Mannar, southeast coast of India. Science of tsunami Hazards, 25(3): 160172.

Sly, P. G. (1978). Sedimentary processes in lakes. In: "Lakes". Lerman, A. (Ed.) Springer, New York, NY, 65-89pp. Doi: 10.1007/978-1-4757-1152-3_3

Stanley, D. J. (1990). Recent subsidence and northeast tilting of the Nile delta, Egypt. Marine Geology, 94(1-2): 147-154. Doi:10.1016/0025-3227(90)90108-V

Stanley, D. J. and Warne, A. G. (1993). Nile Delta: recent geological evolution and human impact. Science, 260(5108): 628-634. Doi:10.1126/science.260.5108.628

Stanley, J. D.; Goddio, F.; Jorstad, T. F. and Schnepp, G. (2004). Submergence of ancient Greek cities off Egypt's Nile Delta-A cautionary tale. GSA TODAY, 14(1): 4-10. Doi:10.1130/1052 5173(2004)014<4:SOAGCO>2.0.CO;2

Stewart Jr, H. B. (1958). Sedimentary reflections of depositional environment in San Miguel lagoon, Baja California, Mexico. AAPG bulletin, 42(11): 2567-2618. Doi:10.1306/0bda5bfa-16bd-11d7 8645000102c1865d

Sutherland, R. A. and Lee, C. T. (1994). Discrimination between coastal subenvironments using textural characteristics. Sedimentology, 41(6): 1133-1145. Doi:10.1111/j.1365-3091.1994.tb01445.x

Torab, M. and Azab, M. (2007). Modern shoreline changes along the Nile Delta coast as an impact of construction of the Aswan High Dam. Geographia Technica, 2(2): 69-76. 